\title{
The effect of predator/prey density and water dynamics on feed intake and growth in spiny lobster larvae (Jasus edwardsii)
}

\author{
Greg G. Smith ${ }^{1 *}$, Luisa Lyall ${ }^{2}$ \& Arthur J. Ritar ${ }^{1}$
}

${ }^{1}$ Marine Research Laboratories, Tasmanian Aquaculture and Fisheries Institute, University of Tasmania, Nubeena Crescent, Taroona, Tasmania 7053, Australia.

${ }^{2}$ Department of Zoology, University of Tasmania, Nubeena Crescent, Taroona, Tasmania 7053, Australia.

* Corresponding author: Arthur.Ritar@utas.edu.au

\begin{abstract}
Consumption of Artemia by phyllosoma of the spiny lobster Jasus edwardsii was examined under static and turbulent conditions. Phyllosoma larvae were stocked at two densities ( 2 or 4 phyllosoma container ${ }^{-1}$; $2 \mathrm{P}$ or $4 \mathrm{P}$ ) and fed juvenile Artemia (1.6mm total length) at two feed rates (1.5 or 0.75 Artemia ml $^{-1}$; $1.5 \mathrm{~A}$ or $0.75 \mathrm{~A}$ ) in $50 \mathrm{ml}$ of seawater. This provided a combination of 4 treatments (2P/1.5A, 2P/0.75A, 4P/1.5A, 4P/0.75A). Daily intake of Artemia by phyllosoma was monitored and assessed relative to moult size and intermoult duration at differing predator-prey densities. Phyllosoma numbers were held constant; in the event of mortality, animals were replaced with others from the same cohort cultured under similar conditions. Phyllosoma endogenous reserves at hatch combined with the lowest ration of 0.75 A was sufficient to ensure normal growth and intermoult duration until Stage II. When phyllosoma were fed for an extended period (several moults), low ration and high phyllosoma density resulted in smaller size and extended intermoult duration. Fluctuations in the feeding pattern of phyllosoma were evident between treatments during the experiment. Phyllosoma with access to more Artemia consumed more, and consumption was reduced prior to a moult, even during early stages of development. The second phase of the study examined the intake of $1.7 \mathrm{~mm}$ juvenile Artemia by phyllosoma and their response to flow-induced turbulence with a combination of two water exchange rates $\left(2.5\right.$ or 5 times $\left.\mathrm{h}^{-1}\right)$ and two inlet positions $(2 \mathrm{~cm}$ above the water surface or $0.5 \mathrm{~cm}$ above the culture vessel bottom and parallel to it). Larvae exposed to slow flow were larger and had a shorter intermoult duration associated with an increased ability to capture and consume more Artemia. Similar numbers of Artemia were consumed during the intermoult in high flow treatments compared to the low flow, albeit over a longer duration. Phyllosoma development between moults required less Artemia to be consumed under static conditions.
\end{abstract}

Key words: Jasus edwardsii, water turbulence, density, flow rate, feed intake, intermoult duration.

\section{Introduction}

The key to sustainable aquaculture of spiny lobsters needs to be based on the successful and consistent hatchery production of juveniles (Ritar et al. 2002). Spiny lobster phyllosoma have the longest and most complex larval history of all decapod crustaceans, involving at least 9 distinct morphological stages and up to two years to metamorphosis as a puerulus; the pre-juvenile phase (Kittaka, 2000). The larval culture requirements for spiny lobsters, including Jasus edwardsii, Panulirus japonicus and Panulirus ornatus are currently under investigation (Matsuda and Yamakawa, 1997; Matsuda, et al. 2003; 
Bourne et al. 2004; Smith et al. 2003, 2004, Smith and Ritar, 2006) with complete larval development to metamorphosis reported in five species (Kittaka, 2000). However, to date larval rearing to the puerulus stage has only been achieved on an experimental scale, with considerable work still required to attain the goal of commercial production. At present the standard diet for larval rearing of phyllosoma is based on ongrown disinfected Artemia (Smith and Ritar, 2006), because no suitable artificial diets are available. Therefore, it is important to optimize phyllosoma growth while minimizing Artemia production, a timeconsuming component of culture.

The interaction between phyllosoma and Artemia and their ability to respond to differing water flow dynamics have important implications for the production of fast growing healthy larvae and may help set the focus for future designs of culture systems. To date, J. edwardsii phyllosoma larvae have been cultured in an array of vessels with distinctly different flows, including static beakers, tubs with circular horizontal flow, vessels with upwelling turbulence and planktonkriesels (Illingworth, 1997; Kittaka, 2000; Ritar, 2001; Smith et al. 2003).

The aims of this study were to assess optimal feeding regimes, the influence of flowinduced turbulence on the feeding ability of early stage phyllosoma, and to provide a focus for future system design. The Artemia consumption per phyllosoma, the intermoult duration, and the size and survival of phyllosoma were measured as treatment responses.

\section{Materials and Methods}

\section{Artemia production}

Artemia cysts (INVE, Great Salt Lake Prime Gold) were hatched in $50 \mathrm{l}$ white fibreglass cones. All hatching and culture of Artemia were conducted using aerated, $1 \mu \mathrm{m}$ filtered ozonated seawater, maintained at $34 \pm 1 \%$ and $28 \pm 1^{\circ} \mathrm{C}$. At hatch (24 h) Artemia nauplii were harvested, rinsed with freshwater and cultured at an initial density of $10 \mathrm{ml}^{-1}$ in $800 \mathrm{l}$ cones. Artemia were fed the micro-alga Chaetoceros muelleri at a cell density $2 \mathrm{x}$ $10^{5}$ cells $\mathrm{ml}^{-1}$ in the culture vessel; algal feeding was supplemented with rice pollard. Culture cones underwent partial harvests on days 4 through 6 to provide daily feed requirements. Phyllosoma were fed 1.6 and $1.7 \mathrm{~mm}$ juvenile Artemia daily during Experiment 1 (total - 5400 Artemia day $^{-1}$ ) and 2 (total - 40800 Artemia day $^{-1}$ ), respectively. Prior to feeding to phyllosoma Artemia were purged with axenic $C$. muelleri and formalin $\left(400 \mu \mathrm{g} \mathrm{g}^{-1}\right)$ for $60 \mathrm{~min}$ to reduce the bacterial content of the food source (Smith and Ritar, 2006).

\section{Experiment 1: Predator - Prey interaction}

Larval selection and culture conditions

Newly hatched phyllosoma were obtained from ovigerous broodstock caught off Flinders Island on Tasmania's north-east coast (40³2' S, $\left.148^{\circ} 16^{\prime} \mathrm{E}\right)$ in June, and maintained at the Marine Research Laboratories in Taroona until hatch during September. Larvae were cultured in $70 \mathrm{ml}$ clear plastic sample jars containing $50 \mathrm{ml}$ of ozonated, UV treated, filtered seawater ( $1 \mu \mathrm{m}$ filtered, $34 \pm 1 \%$ o) gently agitated by air bubbling from an

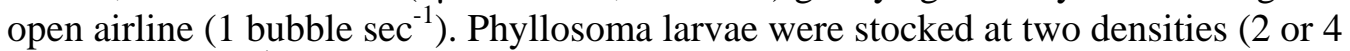
phyllosoma jar ${ }^{-1}$, respectively) and fed $1.6 \mathrm{~mm}$ Artemia at either 1.5 or 0.75 Artemia ml $^{-1}$ (75 or 38 Artemia jar ${ }^{-1}$ respectively, Table 1). All treatments were conducted in quadruplicate. Additional phyllosoma were maintained in $1 \mathrm{l}$ beakers at the same predatorprey densities to supply replacement phyllosoma in the event of treatment mortality, thus maintaining consistent densities throughout the experiment. Growth of replacement 
phyllosoma was homogeneous and representative of that attained in individual treatments. During the study, between $25-50 \%$ of animals were replaced due to deaths, with substitutions primarily in the first 3 days of the study and at the moult to Stages II and III. Jars containing Artemia without phyllosoma ("blanks") were maintained to assess mortality unrelated to phyllosoma predation, and these mortalities were subtracted from the other treatments. Sample jars and replacement beakers were maintained at $18^{\circ} \mathrm{C}$ and randomly suspended within a recirculating temperature control water bath. All culture containers were $75 \%$ immersed in the heated water with unimpeded flow to the sides and bottom of the containers. During daylight hours, light was $0.05 \mu \mathrm{mol} \mathrm{m}^{-2} \mathrm{~s}^{-1}$ on a 12:12 (light:dark) photoperiod cycle. Complete water exchanges were conducted daily at 11am to facilitate the counting of remaining whole and partial/dead Artemia, remove moults, replace dead phyllosoma and to conduct phyllosoma measures.

\section{Phyllosoma feeding}

Phyllosoma larvae were fed their Artemia ration daily by $1 \mathrm{pm}$ and for a minimum duration of $22 \mathrm{~h}$. In all treatments, Artemia were individually counted into culture jars. Artemia numbers for phyllosoma held in $1 \mathrm{l}$ beakers as replacements were determined volumetrically. At the completion of the feed period, the numbers of live Artemia plus those dead or partially eaten were counted in each treatment jar and total Artemia consumption was calculated. Due to low numbers of dead Artemia in the 'blank', and the majority of dead/partial Artemia being predominantly whole, only missing Artemia were calculated as contributing to the consumption total.

Post water exchange and feeding, antibiotics (oxytetracycline hydrochloride 25ppm, Engemycin 100, Intervet, Australia) were added to all replacement beakers. Antibiotics were used to primarily reduce the impact of filamentous bacterial fouling on phyllosoma and remained as a continuous bath until flushed the next day during water exchange.

\section{Monitoring growth and intermoult duration}

Total body length (anterior tip of the cephalic shield to the posterior point of the abdomen) was measured on 20 newly-hatched Stage I phyllosoma and the subsequent $2^{\text {nd }}$, $3^{\text {rd }}, 4^{\text {th }}$ and $5^{\text {th }}$ developmental stages on days $13,25,37$ and 49 , respectively, as described by Lesser (1978). Measurements were obtained using an overhead projection microscope (Nikon 6C profile projector, 20 times magnification). The pattern of phyllosoma moulting was recorded daily with the intermoult duration calculated as the mean period for $50 \%$ of animals to moult from one stage to the next in individual replicates. Phyllosoma culture was conducted for $49 \mathrm{~d}$, sufficient for the most advanced treatments to attain Stage V of larval development.

\section{Experiment 2: Effect of flow on Artemia consumption}

Larval selection and monitoring

Phyllosoma larvae were stocked at a density of $40 \mathrm{l}^{-1}$ into quadruplicate $1.6 \mathrm{l}$ plastic flat-bottomed beakers and cultured to Stage IV (38 d after hatch). All beakers were fed $1.74 \pm 0.03 \mathrm{~mm}$ Artemia at a rate of $1.5 \mathrm{ml}^{-1} \mathrm{day}^{-1}$; the same phyllosoma Artemia density ratio as $2 \mathrm{P} / 1.5 \mathrm{~A}$ in the first study. Artemia numbers for daily feeds were determined volumetrically after the average of three $75 \mathrm{ml}$ sub samples of freshly harvested/purged Artemia was taken. Phyllosoma larvae were fed Artemia by $1 \mathrm{pm}$ and left to feed overnight. Each morning at 11am, larvae were removed and placed in fresh containers and the consumption of Artemia assessed. Phyllosoma survival was monitored every second day with the average used to calculate consumption on intermediate days. Phyllosoma had a minimum daily feeding duration of $22 \mathrm{~h}$ before Artemia consumption was assessed. The 
difference between the number of Artemia fed at time 0 and those remaining (alive, dead/ partial) were presumed eaten. Artemia were additionally cultured without phyllosoma (blanks) to assess mortality unrelated to feeding, mortality was $<2 \%$; thus no adjustments were made to consumption calculations during this component of the study. The monitoring of phyllosoma size and intermoult duration remained as previously described. Survival was recorded on days 13, 25 and 38 corresponding to Stages II, III and IV, respectively.

\section{Larval culture conditions}

Phyllosoma were subjected to water turbulence in the beakers produced by two inlet positions, either top ( $2 \mathrm{~cm}$ from the water surface and near the side) or bottom $(0.5 \mathrm{~cm}$ from the beaker bottom, parallel and directed diagonally across it), and two water flow rates, either slow (2.5 exchanges $\mathrm{h}^{-1}$ ) or fast $\left(5\right.$ exchanges $\left.\mathrm{h}^{-1}\right)$. Thus for:

- a top inlet and a slow flow rate, water was evenly dispersed throughout the beaker water column without producing a dominant top to bottom circular current.

- a bottom inlet and slow flow rate, water was dispersed in a horizontal action on the beaker floor, with mixing extending slowly into the upper layers.

- a top inlet with fast flow rate, water moved in a turbulent circular top to bottom current, evenly mixing the water column.

- a bottom inlet with fast flow rate, water moved turbulently across the beaker floor then upwards at the opposite side of the beaker towards the water surface, producing a rapid bottom to top circular movement.

Water supply to the larval rearing system was flow-through, filtered to $1 \mu \mathrm{m}$, ozonated as described by Ritar et al. (2006) and temperature controlled at $18 \pm 1^{\circ} \mathrm{C}$ (heat/chill units, APAC CO10PHH7AA, Airco, Hobart, Australia). Light was provided at $0.05 \mu \mathrm{mol} \mathrm{m}^{-2} \mathrm{~s}^{-1}$, measured at the water surface on a 12:12 (light:dark) photoperiod cycle. The lighting system comprised a series of fluorescent lamps positioned $2 \mathrm{~m}$ above the culture containers fitted with covers underneath the lamps to provide a reflected diffused lighting source. $J$. edwardsii phyllosoma are strongly photopositive for the first $1-2$ days post-hatch, thereafter they display minimal phototactic response.

\section{Statistics}

Statistical analyses were conducted using multifactor analysis of variance with TukeyKramer HSD tests for post-hoc comparison. Arcsin $\sqrt{ }$ transforms were performed on percentage data. $P<0.05$ was considered significantly different (Sokal \& Rohlf, 1995). Data are presented as mean \pm SEM. Statistics were executed using JMP version 3.1. (SAS Institute Inc.).

\section{Results}

Experiment 1: Predator-prey density

Growth and intermoult duration

There was no significant effect of phyllosoma or Artemia density on total length at Stage II (Fig. 1). Phyllosoma stocking density and interactions with Artemia density significantly affected the total length of Stage III phyllosoma. This effect was accentuated with culture to Stage IV, with animals in the highest phyllosoma density and fed the least Artemia (4P/0.75A) being significantly smaller than all other groups.

Phyllosoma intermoult duration followed a similar pattern to that of total length. The intermoult duration of Stage I phyllosoma (between hatch and the first moult) was 
unaffected by treatment conditions (Fig. 2). The intermoult duration of Stage II phyllosoma (duration between Stage II and III moults) and subsequently Stage III phyllosoma (duration between Stage III and IV moults) were longer in the combination of high phyllosoma and low Artemia densities. By day 49, all phyllosoma in treatment 2P/1.5A had completed the moult to Stage V, whereas treatments $2 \mathrm{P} / 0.75 \mathrm{~A}$ and $4 \mathrm{P} / 1.5 \mathrm{~A}$ were 62.5 and $75 \%$ complete, respectively, while $4 \mathrm{P} / 0.75 \mathrm{~A}$ had only just completed the moult to Stage IV and had not commenced the moult to Stage V (Fig. 3).

\section{Artemia consumption}

There were several distinctive patterns of daily Artemia consumption (Fig. 3). The greatest number of dead/partial Artemia occurred at the highest Artemia to phyllosoma ratio (2P/1.5A). Almost all available Artemia were consumed on a number of occasions in the lowest Artemia to phyllosoma ratio (4P/0.75A). Artemia consumption declined markedly in all treatments once or twice during an intermoult period, and always immediately prior to a moult event.

The proportion of the total Artemia eaten per phyllosoma increased as the amount of food available became more limited (Fig. 3). Consequently, a similar reduction in dead/partial Artemia was also exhibited. An increase in phyllosoma density and reduced Artemia density resulted in minimal amounts of partial/dead Artemia remaining.

Artemia consumption was significantly affected by phyllosoma and Artemia density. Treatment 2P/1.5A, with the highest Artemia to phyllosoma ratio of 37.5 Artemia per phyllosoma, consistently showed greater numbers of Artemia consumed per stage and cumulatively for all three stages (Fig. 4). In the treatments where the ratio of Artemia to phyllosoma were the same (2P/0.75 and 4P/1.5A, 18.75 Artemia available per phyllosoma), consumption within each stage remained equivalent, although cumulative consumption (Stages I, II and III) was higher where Artemia density was greater (4P/1.5A). High phyllosoma density coupled with low Artemia density (4P/0.75A) resulted in the lowest cumulative total Artemia consumption for stages I, II and III (Fig 4).

Experiment 2: Effects of flow and inlet positioning

Growth, survival and intermoult duration

Survival to Stage IV was variable between replicates, thus no significant effect of either flow or positioning was noted. At the completion of the study, survival was $68.2 \pm$ $7.9 \%$ for the bottom slow treatment, and $42.7 \pm 2.8 \%$ for the bottom fast treatment. The top slow and top fast treatments attained intermediate levels of survival of $54.2 \pm 8.9 \%$ and $53.1 \pm 5.9 \%$, respectively. Flow had a significant effect on size, with Stage IV phyllosoma significantly larger in the top slow and bottom slow treatments (5.05 \pm 0.04 and $5.05 \pm 0.03 \mathrm{~mm}$, respectively) compared to those in the top fast and bottom fast treatments (4.74 \pm 0.02 and $4.68 \pm 0.04 \mathrm{~mm}$, respectively).

There was no significant effect of flow or positioning on the duration of Stage I (period from hatch to the moult to Stage II, Fig. 5). However, the duration of the Stage II (period from the Stage II moult to the Stage III moult) was shortest in the top slow treatment while those in the bottom fast were the longest, with bottom slow and top fast demonstrating intermediate durations. Stage III (period from the Stage III moult to the Stage IV moult) was shorter in the slow flow treatments compared to those in the fast flow treatments. This was further demonstrated in the total culture duration from hatch to the completion of Stage III (moult to Stage IV), with a minimum of 32.9 days in the top slow treatment and a maximum of 37.3 in the bottom fast treatment.

\section{Artemia consumption}


There were a number of minor differences in the phyllosoma Stage-specific Artemia consumption (Fig. 6). Stage I phyllosoma in the bottom-slow treatment consumed more Artemia than all other treatments, while Stage II phyllosoma from the top-slow treatment consumed more than those from the top-fast treatment. Artemia consumption during Stage III, and also the cumulative total of Stages I, II and III, did not differ significantly between treatments. Inlet positioning did not have a significant effect on consumption. Artemia consumption by phyllosoma followed the same pattern as in Experiment 1, with one-two peaks in consumption mid-stage, reduced consumption prior to a moult, and increased post-moult regardless of treatment, albeit at lower levels over a significantly longer timeframe for fast flow treatments (Fig. 7). It is worth noting that more Artemia were consumed to attain Stage IV of development when exposed to slow turbulence in the second study (593.8 \pm 5.8 Artemia), compared to the same treatment under static conditions in the first study (Treatment $1-2 \mathrm{P} / 1.5 \mathrm{~A}$; $521 \pm 9.7$ Artemia) even though the duration to Stage IV was the same.

\section{Discussion}

J. edwardsii phyllosoma typically have a 10-12 day intermoult duration between hatch and the moult to Stage II, with a point-of-no-return for commencement of feeding of 4 days, therefore they have limited endogenous reserves (Abrunhosa and Kittaka, 1997). Even at the minimum Artemia feed ration there was no influence on phyllosoma size or intermoult duration at Stage II. The minimum ration was adequate, while excess reserves from larger rations may have been stored for use during later stages (Mikami and Takashima, 1993). When insufficient feed is provided, moulting may be delayed by a number of days (Tong et al. 1997). When feed is not available, reserves are depleted, phyllosoma do not moult and death from starvation occur 12-20 days post-hatch (Tong et al., 1997; Smith et al. 2003). When phyllosoma were fed for in excess of 45 days, those fed the lowest numbers of Artemia were smaller with longer intermoult durations; they were just completing the moult to Stage IV while all other groups had commenced the moult to Stage V. Vijayakumaran and Radhakrishnan (1986) also noted substantial moult delays in Panulirus homarus phyllosoma when fed lower Artemia rations, with the lowest ration not moulting at all while others undergoing intermediate stages of development rather than direct moulting to the next morphological stage. It may be that longer intermoult durations between stages are a prelude to additional instars. During our study we did not record additional instars suggesting that the lowest feed rate supports a normal moulting pattern, albeit somewhat delayed.

Phyllosoma with access to the greatest number of Artemia consumed more, which is common in crustacean culture, and may provide reserves for use during later stages (Inoue, 1965; Vijayakumaran and Radhakrishnan, 1986; Tong et al. 1997, 2000; Thessalou-Legaki et al. 1999). The significance of a carryover of reserves has been noted previously (Mikami and Takashima, 1993) and can positively affect size and reduce intermoult duration. Phyllosoma are active predators, able to locate, catch and consume Artemia even at low densities, although at high density there is an increase in the frequency of chance encounters contributing to consumption (Thessalou-Legaki, et al. 1999). Thus, under the influence of high prey densities the importance of active foraging by phyllosoma is reduced and may assist in the conservation of energy stores.

Where two treatments had the same phyllosoma/Artemia ratio (4P/1.5A and 2P/0.75A), total Artemia consumption was greatest where prey density was highest (4P/1.5A), irrespective of phyllosoma number. Prior to this study, the interactions between phyllosoma at low density and their food source, Artemia, were unclear (Smith and Ritar, 
2006). This study suggests, at least during early development, that interaction between phyllosoma plays a lesser role in reducing intake than does access to food, and reinforces the suggestion by Tong et al. (1997) that prey capture is related to prey density.

The use of small juvenile Artemia during our study allowed clear differentiation of daily intake across all feed treatments. The reduction in feeding prior to the moult was a prominent feature observed during all stages, previously only reported for more advanced phyllosoma (Tong et al. 1997). In treatments where food was limiting, i.e. 4P/0.75A, there were very few dead/partial Artemia remaining. Whole Artemia may have been consumed during initial feed encounters, although it is likely that phyllosoma returned to dead/partials after the majority of live feed had been eaten.

Comparison between the consumption by J. edwardsii phyllosoma in static culture in our study with that of Tong et al. (1997) highlights the significance of Artemia size. During our study greater numbers of smaller Artemia were consumed per day, equating to approximately $75 \%$ of the biomass consumed in the Tong et al. (1997) study. This suggests that increased effort is required to capture a similar biomass of smaller Artemia when animals are fed to satiation. When the optimal intake can not be attained, the moult interval is lengthened and the moult increment is reduced (Vijayakumaran and Radhakrishnan, 1986). Tong et al. (2000) found a similar pattern of time-limiting capture ability when examining the consumption of $1 \mathrm{~mm}$ and 2-3 mm Artemia. So not only does the density of Artemia affect the ability of phyllosoma to catch prey, but also, the size of Artemia impacts on the biomass of food consumed.

During early stages of development (Stages I-IV), we noted that phyllosoma were unable to swim in the 'typical' circular feeding pattern when exposed to constant turbulence experienced in the fast treatments, and instead were swept along with the prevailing current. Phyllosoma in the slow treatments caught a greater number of Artemia per day in the absence of constant turbulence, both phyllosoma and Artemia were located on the jug bottom, except for the first 1 - 2 days when phyllosoma may be phototactic and actively swim to the surface of the container. The result of increased food consumption and reduced capture effort by phyllosoma in slow treatments produced larger animals in a shorter time, and perhaps a store of energy for sustenance during periods of low food availability. This may be a strategy to optimise their chance of survival during their extended planktonic life-phase. To the contrary, phyllosoma in the fast treatments caught less Artemia per day and endured a longer intermoult period to attain the same stage of development, albeit at a smaller size. While restricted intake reduced growth and increased the intermoult period there were no additional instars (moult phase whereby growth occurs without a change in morphology) as noted by Vijayakumaran and Radhakrishnan (1986).

During this relatively short study we noted that constant turbulence impeded phyllosoma from capturing Artemia while previously in studies of longer duration slow flow or no flow has been associated with fouling; due possibly to organisms clumping together while feeding (Smith unpublished). This creates a paradoxical situation whereby some turbulence is desirable to reduce adverse phyllosoma interaction and facilitate predator-prey mixing, while excess turbulence reduces food intake. Therefore, we are currently investigating the use of intermittent turbulence within suitably designed culture vessels; a pulse of incoming water facilitates predator-prey mixing interspersed with static periods to facilitate prey capture and feeding opportunities.

The provision of larger Artemia may also improve phyllosoma growth and survival by improving the feed efficiency of capture events. Large Artemia have a reduced tendency to swarm and assume a homogeneous distribution (Gulbrandsen, 2001) that may assist in their capture. 


\section{Conclusion}

In summary, the provision of suboptimal amounts of diet to phyllosoma manifests itself in reduced phyllosoma size at subsequent moults and a longer intermoult duration. By increasing Artemia density there is a concomitant increase in their consumption by phyllosoma. During phyllosoma development, constant high water turbulence should be avoided to allow capture of Artemia. Future improvements in culture vessel design should incorporate optimum water flow dynamics for the distribution of predator and prey to maximise feeding opportunities.

\section{Acknowledgements}

This research was funded by the Fisheries Research and Development Corporation, Rock Lobster Enhancement and Aquaculture Subprogram: Propagation of the Southern Rock Lobster (Jasus edwardsii) in Tasmania (Project number 2003/212). We thank Craig Thomas, Ed Smith and Bill Wilkinson for assistance in the production of live feeds and phyllosoma husbandry.

\section{References}

Abrunhosa, F.A., Kittaka, J. 1997. Effect of starvation on the first larvae of Homarus americanus (Decapoda, Nephropidae) and phyllosomas of Jasus verreauxi and $J$. edwardsii (Decapoda, Palinuridae). Bulletin of Marine Science 6, 73-80.

Bourne, D.G., Young, N., Webster, N., Payne, M., Salmon, M., Demel, S., Hall, M. 2004. Microbial community dynamics in a larval aquaculture system of the tropical rock lobster, Panulirus ornatus. Aquaculture 242, 31-51.

Gulbrandsen, J. 2001. Artemia swarming - Mechanisms and suggested reasons. Journal of Plankton Research 23, 659-669.

Illingworth, J., Tong, L.J., Moss, G.A., Pickering, T.D. 1997. Upwelling tank for culturing rock lobster (Jasus edwardsii) phyllosomas. Marine and Freshwater Research 48, 911914.

Inoue, M. 1965. On the relation of amount of food taken to the density and size of food and water temperature in rearing the phyllosoma of the Japanese spiny lobster, Panulirus japonicus (V. Siebold). Bulletin of the Japanese Society of Scientific Fisheries 31, 903-906.

Kittaka, J. 2000. Culture of larval spiny lobsters. In: Phillips, B.F., Kittaka, J. (Eds.), Spiny lobsters: Fisheries and culture $2^{\text {nd }}$ Ed. Fishing News Books, Blackwell Science, Gray Publishing, Kent, 508-532.

Lesser, J.H.R. 1978. Phyllosoma larvae of Jasus edwardsii (Hutton) (Crustacea: Decapoda: Palinuridae) and their distribution off the east coast of the North Island, New Zealand. New Zealand Journal of Marine and Freshwater Research 12, 357-370.

Matsuda, H., Yamakawa, T. 1997. Effects of temperature on growth of the Japanese spiny lobster, Panulirus japonicus (V. Siebold) phyllosomas under laboratory conditions. Marine and Freshwater Research 48, 791-796.

Matsuda, H., Takenouchi, T., Yamakawa, T. 2003. Diel timing of molting and metamorphosis of Panulirus japonicus phyllosoma larvae under laboratory conditions. Fisheries Science 69, 124-130.

Mikami, S. and Takashima, F. 1993. Effects of starvation upon survival, growth and molting interval of the larvae of the spiny lobster Panulirus japonicus (Decapoda, Palinuridae). Crustaceana 64, 137-142. 
Ritar, A.J. 2001. The experimental culture of phyllosoma larvae of the southern rock lobster (Jasus edwardsii) in a flow-through system. Aquaculture Engineering 24, 149156.

Ritar A.J., Thomas C.W., Beech A.J. 2002. Feeding Artemia and shellfish to phyllosoma larvae of southern rock lobster (Jasus edwardsii) Aquaculture 212, 179-190.

Ritar, A.J., Smith, G.G., Thomas, C.W. 2006. The use of seawater ozonation to improve the survival of southern rock lobster, Jasus edwardsii, phyllosoma larvae in culture from egg to juvenile. Aquaculture 261, 1014-1025.

Smith, G.G., Thompson, P.A., Ritar, A.J., Dunstan, G.A. 2003. Effects of starvation and feeding on the fatty acid profiles of Stage I phyllosoma of the spiny lobster, Jasus edwardsii. Aquaculture Research 34, 419-426.

Smith, G., Brown, M., Ritar, A. 2004. Feeding juvenile Artemia enriched with ascorbic acid improves larval survival in the spiny lobster Jasus edwardsii. Aquaculture Nutrition 10, 105-112.

Smith, G.G., Ritar, A.J. 2006. The influence of animal density and water turbulence on growth and survival of cultured spiny lobster (Jasus edwardsii) larvae. Aquaculture 258, 404-411.

Sokal, R.R., Rohlf, J.F. 1995. Biometry: The principles and practice of statistics in biological research. Freeman. New York, 468p.

Thessalou-Legaki, M., Peppa, A., Zacharaki, M. 1999. Facultative lecithotrophy during larval development of the burrowing shrimp Callianassa tyrrhena (Decapoda: Callianassidae). Marine Biology 133, 635-642.

Tong, L.J., Moss, G.A., Paewai, M.M., Pickering, T.D. 1997. Effect of brine-shrimp numbers on growth and survival of early-stage phyllosoma larvae of the rock lobster Jasus edwardsii. Marine and Freshwater Research 48, 935-940.

Tong, L.J., Moss, G.A., Paewai, M.M., Pickering, T.D. 2000. Effect of temperature and feeding rate on the growth and survival of early and mid-stage phyllosomas of the spiny lobster Jasus edwardsii. Marine and Freshwater Research 51, 235-241.

Vijayakumaran, M., Radhakrishnan, E.V. 1986. Effects of food density on feeding and moulting of phyllosoma larvae of the spiny lobster Panulirus homarus (Linnaeus). In: Proceedings of the $4^{\text {th }}$ Symposium of Coastal Aquaculture. Marine Biological Association of India. 1281-1285. 
Table 1. Phyllosoma and Artemia treatment parameters (Experiment 1).

\begin{tabular}{lcccc}
\hline Treatment & $\begin{array}{c}\text { Phyllosoma } \\
\text { number }\end{array}$ & $\begin{array}{c}\text { Artemia } \\
\text { density } \mathbf{~ m}^{\mathbf{1}}\end{array}$ & $\begin{array}{c}\text { Artemia } \\
\text { available per } \\
\text { phyllosoma }\end{array}$ & $\begin{array}{c}\text { Phyllosoma } \\
\text { density } \mathbf{~}^{-1}\end{array}$ \\
\hline 1-2P/1.5A & 2 & 1.5 & 37.5 & 40 \\
2-4P/1.5A & 4 & 1.5 & 18.75 & 80 \\
3-2P/0.75A & 2 & 0.75 & 19 & 40 \\
4-4P/0.75A & 4 & 0.75 & 9.5 & 80 \\
\hline \hline
\end{tabular}




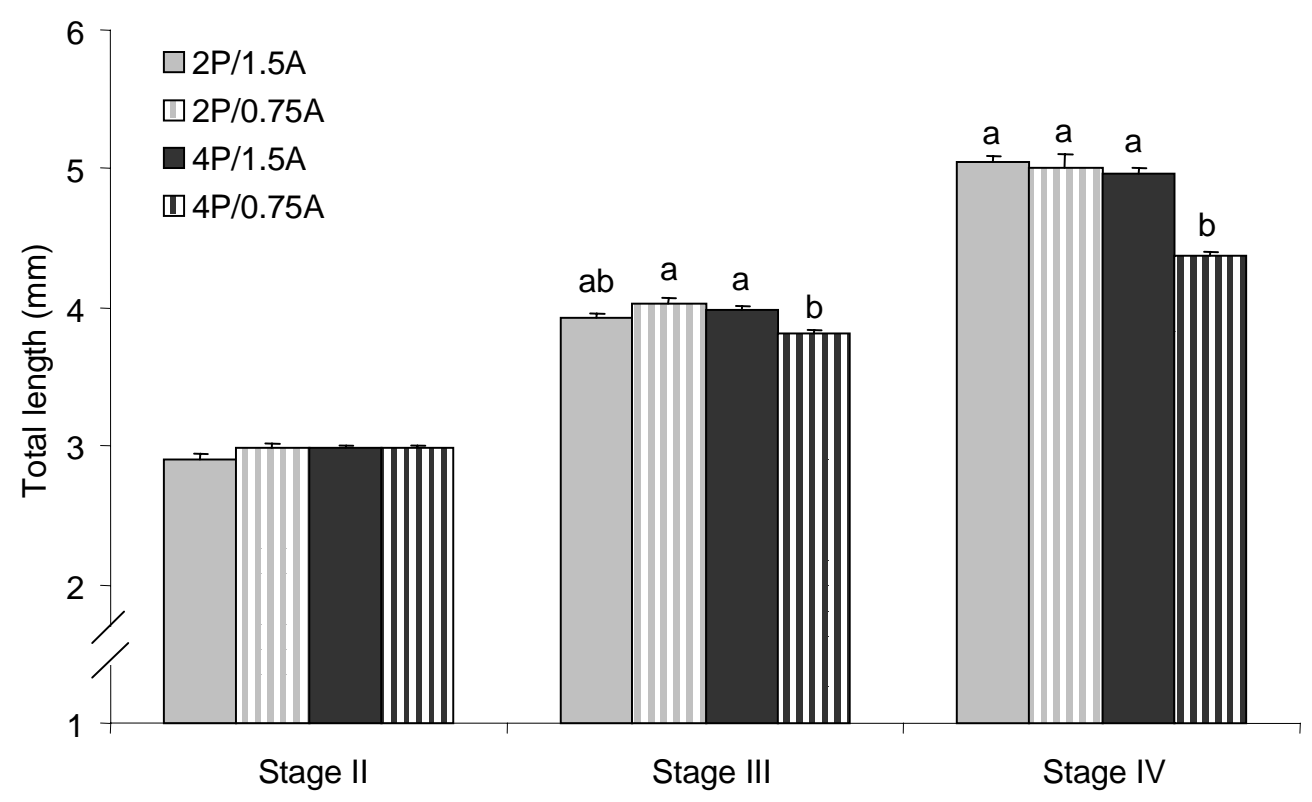

Fig. 1. Total length (mm) of phyllosoma at Stages II, III, and IV. Treatments were a combination of predator density ( 2 or 4 phyllosoma) and prey density (1.5 or 0.75 Artemia $\mathrm{ml}^{-1}$ ), designated as $2 \mathrm{P} / 1.5 \mathrm{~A}, 4 \mathrm{P} / 1.5 \mathrm{~A}, 2 \mathrm{P} / 0.75 \mathrm{~A}$ or $4 \mathrm{P} / 0.75 \mathrm{~A}$ in $50 \mathrm{ml}$ of water in quadruplicate. Different letters denote a significant difference in phyllosoma length within a stage. 


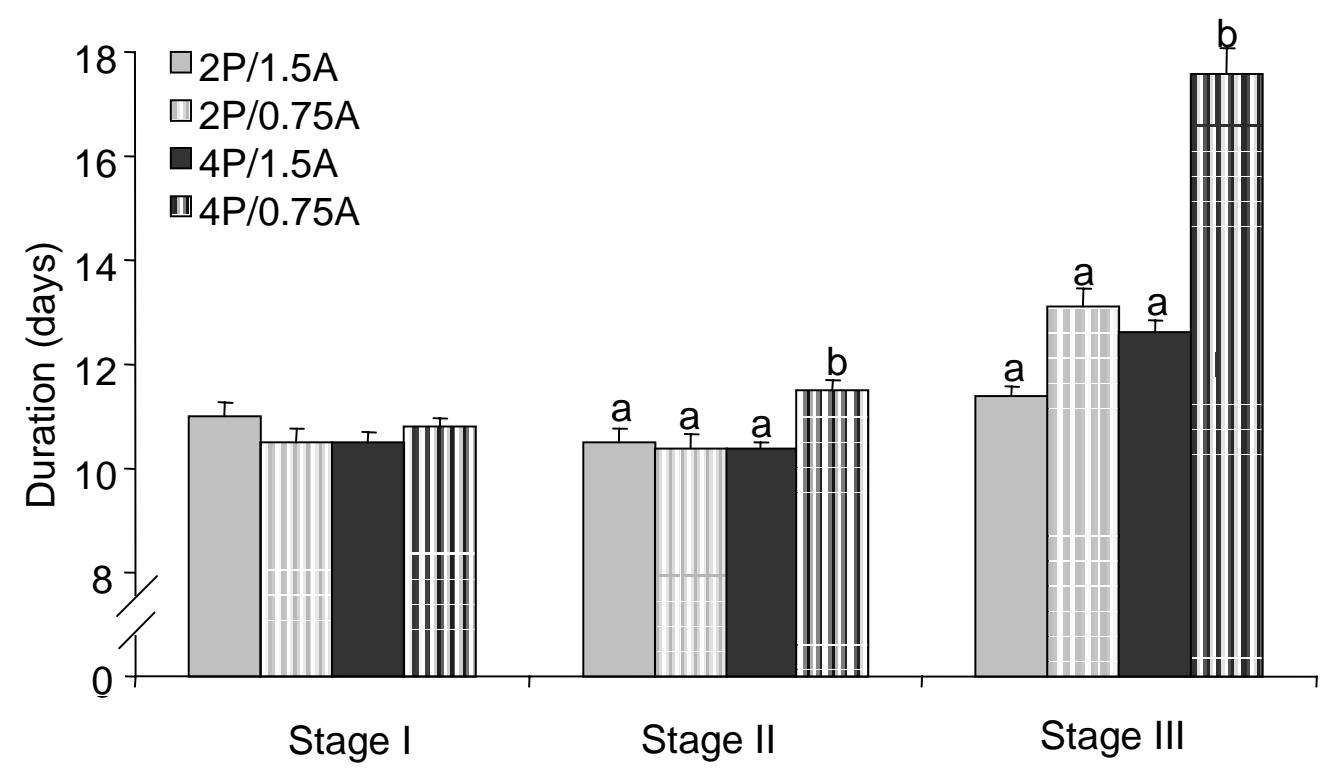

Fig. 2. Intermoult duration for Stage I, II and III phyllosoma. Treatments were a combination of predator density ( 2 or 4 phyllosoma) and prey density (1.5 or 0.75 Artemia $\mathrm{ml}^{-1}$ ), designated as $2 \mathrm{P} / 1.5 \mathrm{~A}, 4 \mathrm{P} / 1.5 \mathrm{~A}, 2 \mathrm{P} / 0.75 \mathrm{~A}$ or $4 \mathrm{P} / 0.75 \mathrm{~A}$ in $50 \mathrm{ml}$ of water in quadruplicate. Different letters denote a significant difference in intermoult duration within a stage. 

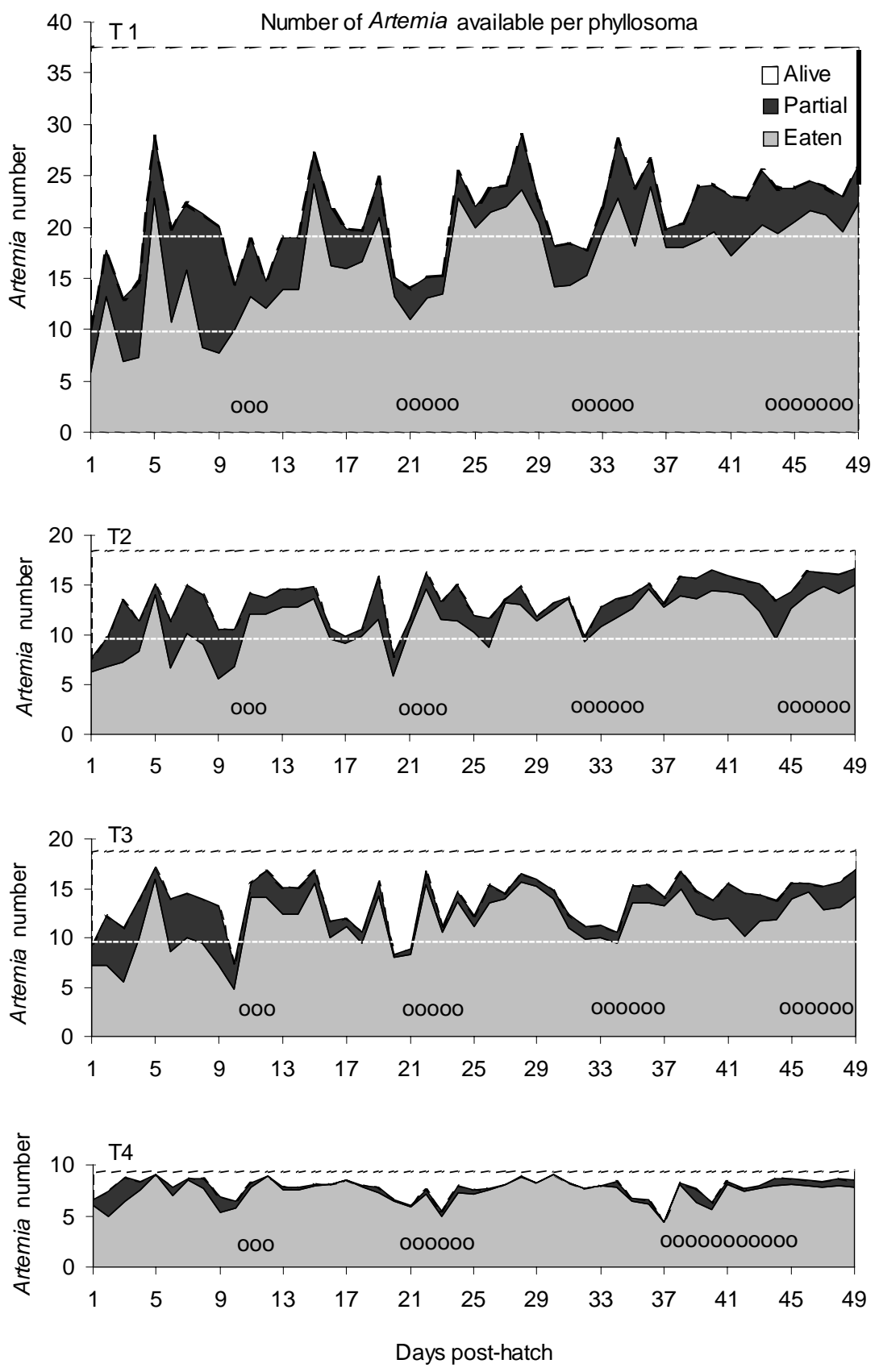

Fig. 3. Pattern of daily Artemia consumption by phyllosoma. Treatments were a combination of predator density ( 2 or 4 phyllosoma) and prey density (1.5 or 0.75 Artemia $\mathrm{ml}^{-1}$ ), designated as $2 \mathrm{P} / 1.5 \mathrm{~A}, 4 \mathrm{P} / 1.5 \mathrm{~A}, 2 \mathrm{P} / 0.75 \mathrm{~A}$ or $4 \mathrm{P} / 0.75 \mathrm{~A}$ in $50 \mathrm{ml}$ of water in quadruplicate. Grey shaded regions illustrate the number of Artemia eaten, black shaded regions represent partial or dead Artemia and white regions were live Artemia. Black broken lines illustrate the maximum number of Artemia available per phyllosoma, the white broken lines demonstrate maximum Artemia availability in other treatments. The circles near the horizontal axes of each graph are an indication of the timing and duration of the moults. Note that 4P/0.75A underwent three moults attaining Stage IV, while the other treatments had completed or commenced the fourth moult to Stage V. 


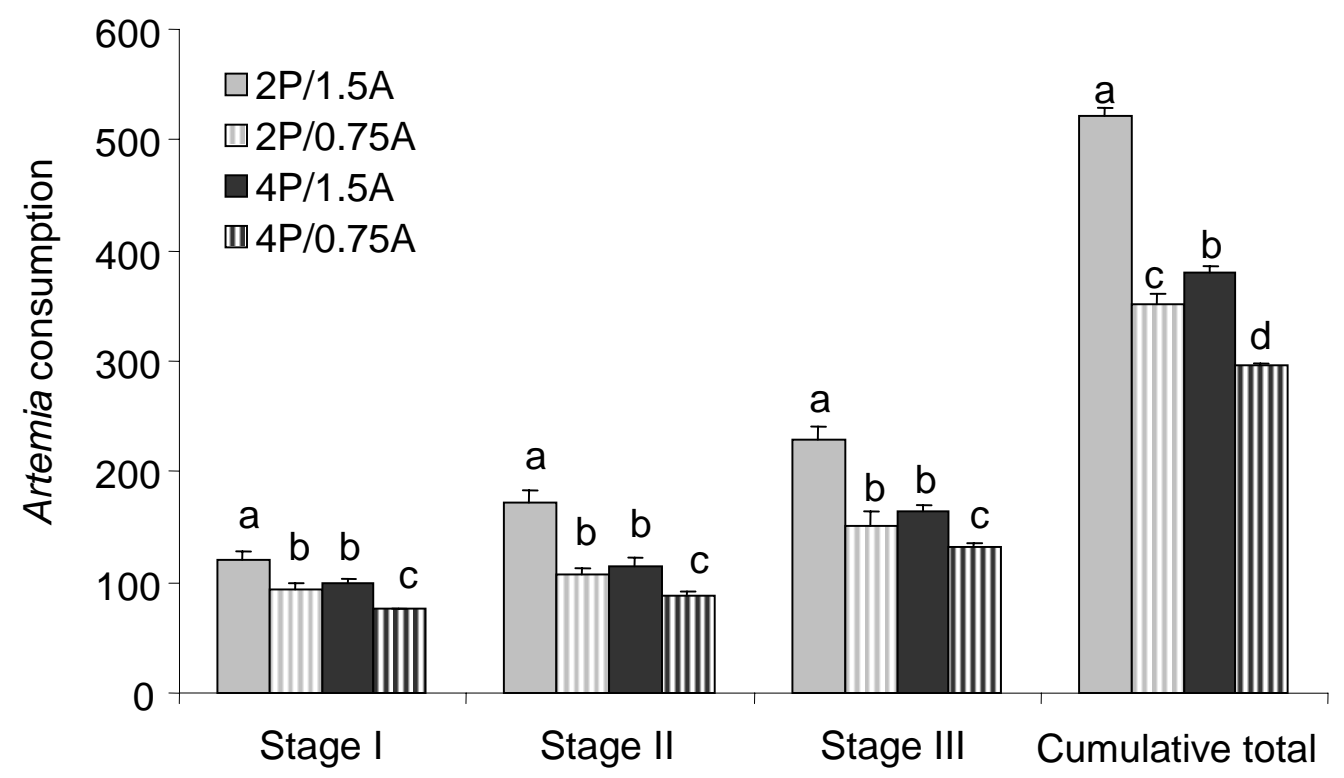

Fig. 4. Number of Artemia consumed by phyllosoma during each stage and the cumulative total consumption during Stages I, II and III. Treatments were a combination of predator density ( 2 or 4 phyllosoma) and prey density (1.5 or 0.75 Artemia $\mathrm{ml}^{-1}$ ), designated as $2 \mathrm{P} / 1.5 \mathrm{~A}, 4 \mathrm{P} / 1.5 \mathrm{~A}, 2 \mathrm{P} / 0.75 \mathrm{~A}$ or $4 \mathrm{P} / 0.75 \mathrm{~A}$ in $50 \mathrm{ml}$ of water in quadruplicate. Different letters denote a significant difference in Artemia consumption within a stage. 


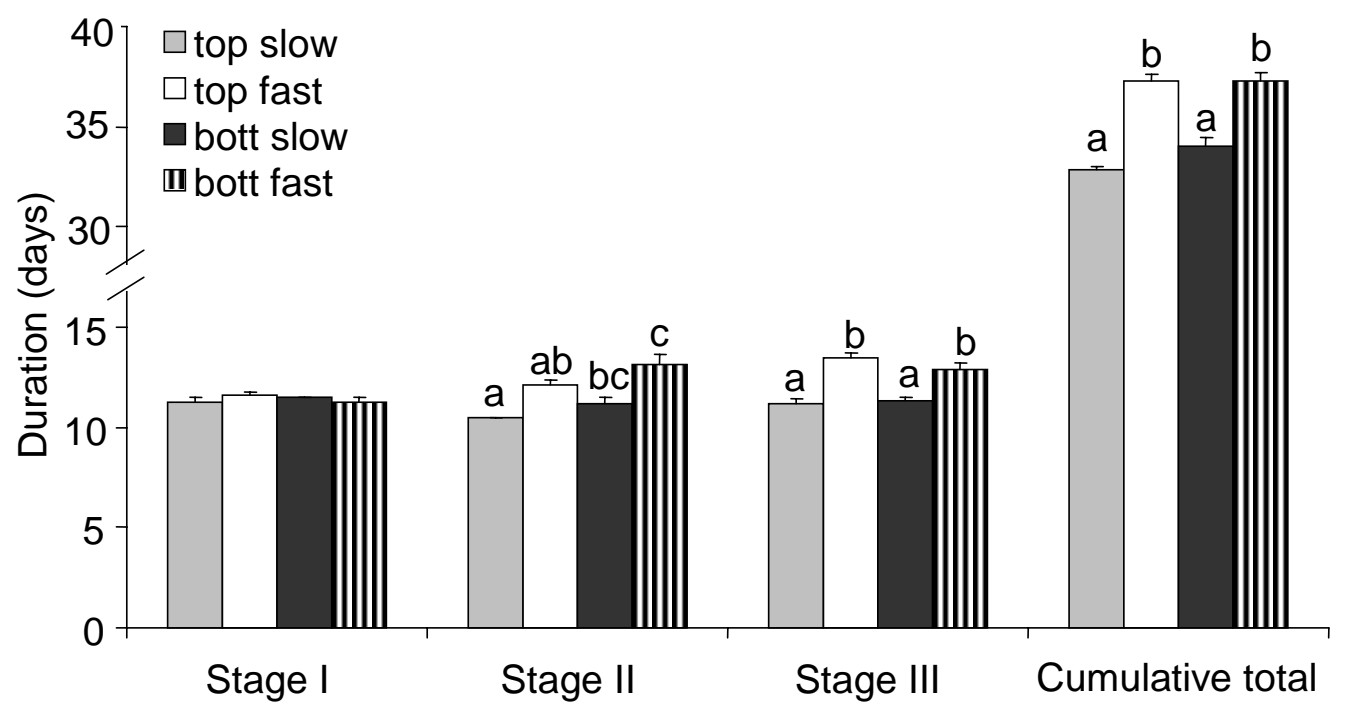

Fig. 5. Duration of each phyllosoma stage and the cumulative total duration of Stages I, II and III. Treatments were a combination of different water inlet positions of top $(2 \mathrm{~cm}$ above the water surface) or bottom $(0.5 \mathrm{~cm}$ above the beaker bottom and parallel to it) and water flow rates of slow (2.5 exchanges $\mathrm{h}^{-1}$ ) or fast $\left(5\right.$ exchanges $\left.\mathrm{h}^{-1}\right)$. Different letters denote a significant difference in intermoult duration within a stage. 


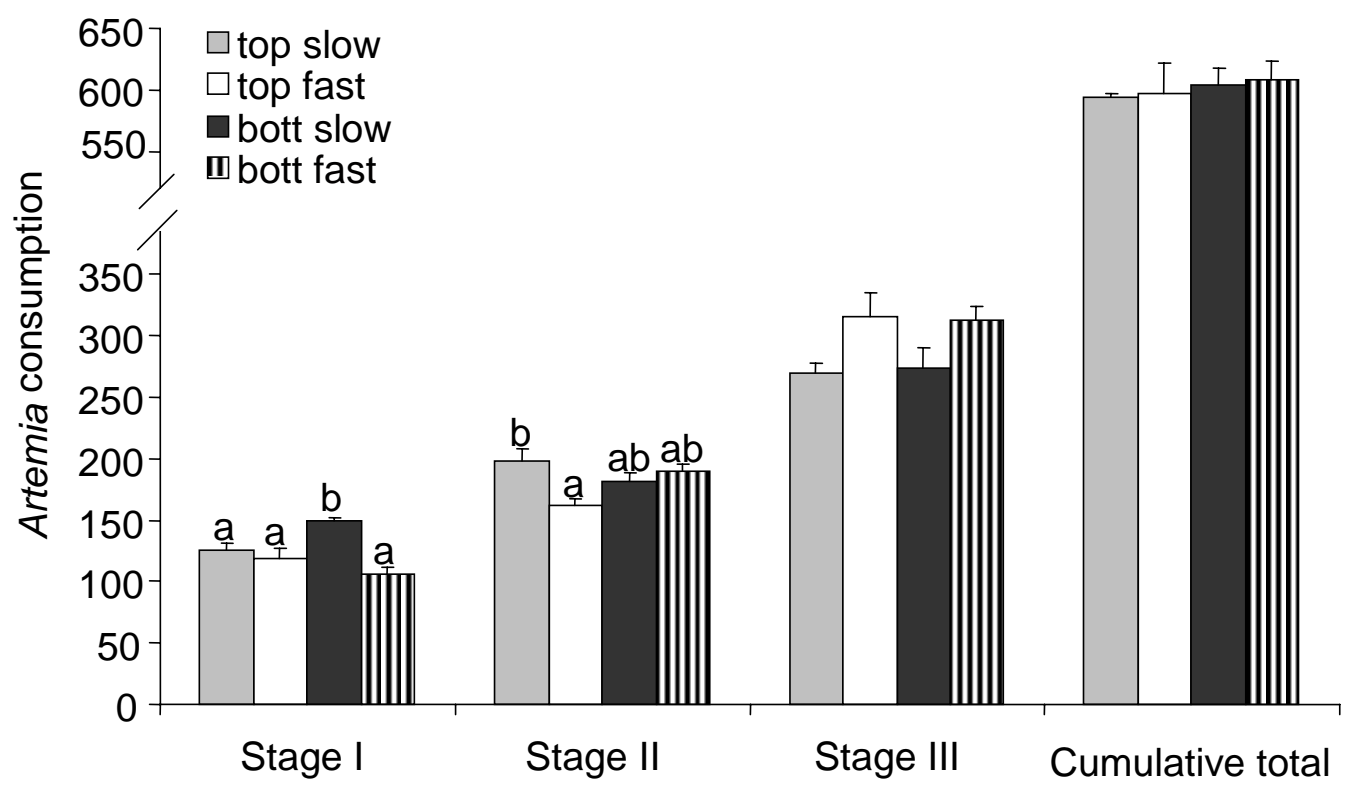

Fig. 6. Number of Artemia consumed by phyllosoma during each stage and the cumulative total consumption during Stages I, II and III. Treatments were a combination of different water inlet positions of top ( $2 \mathrm{~cm}$ above the water surface) or bottom $(0.5 \mathrm{~cm}$ above the beaker bottom and parallel to it) and water flow rates of slow (2.5 exchanges $\mathrm{h}^{-1}$ ) or fast (5 exchanges $\mathrm{h}^{-1}$ ). Different letters denote a significant difference in Artemia consumption. 


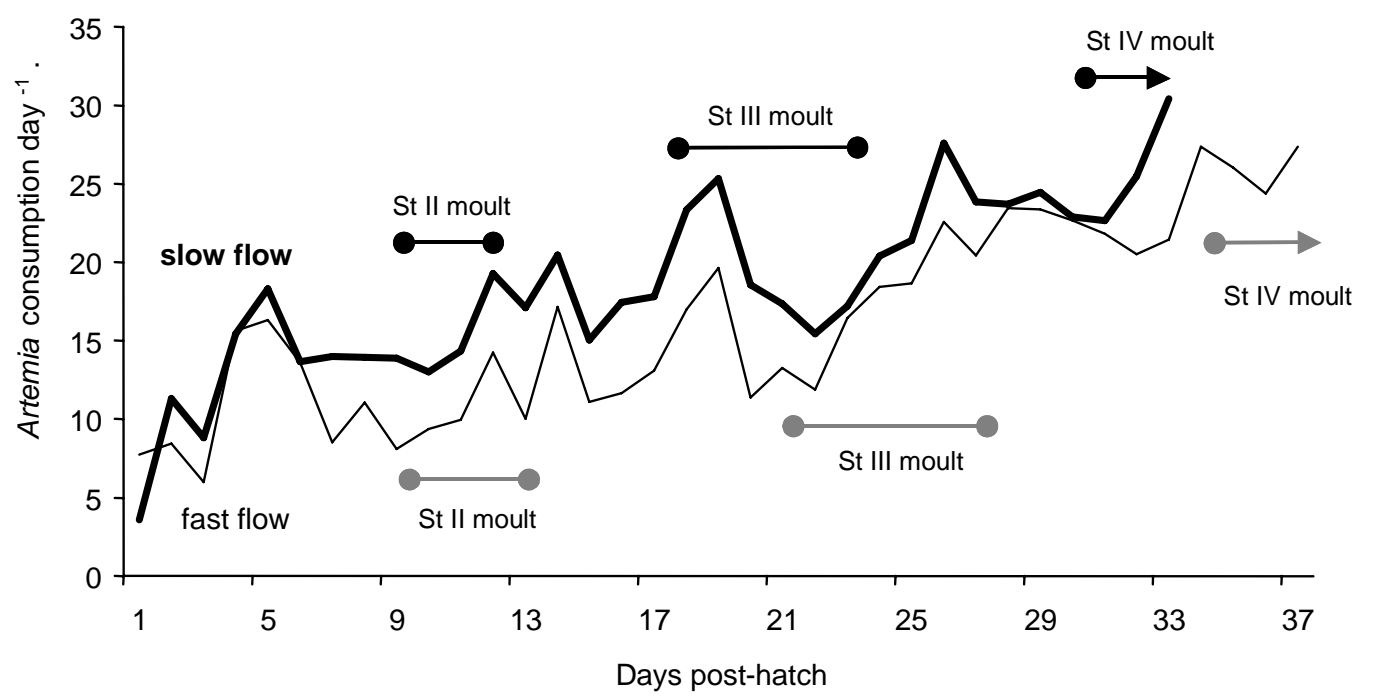

Fig. 7. Pattern of daily Artemia consumption by phyllosoma. There was no significant effect of inlet position on consumption therefore data was pooled for fast and slow-flow treatments. The timing and duration of moulting is noted by horizontal bars at Stages II, III and IV (black: slow flow; grey: fast flow). 